Recibido: 11 Septiembre / Aceptación: 28 Septiembre Ensayo

\title{
Inclusión y exclusión desde mi silla de ruedas
}

\author{
Julián Andrés Cantillo Murcia \\ Estudiante de Psicología \\ Universidad Surcolombiana \\ traico6@hotmail.com
}

En este ensayo ${ }^{1}$ revisa de manera reflexiva y crítica mi experiencia de vida desde una silla de ruedas. Lo hago para establecer en qué consiste la inclusión y la exclusión social, cómo opera y cómo puede enfrentársela basado en aportes de la psicología y en diferentes normas legales como la Declaración de Salamanca (1994), la Declaración de los Derechos Humanos (1948) y el decreto nacional 366 de 2009, entre tantos otros, que reafirman el derecho a la educación de todas las personas y la obligatoriedad para las instituciones educativas de organizar servicios pedagógicos especializados de apoyo a mis semejantes.

El escrito es también una aproximación a la investigación autobiográfica, según Hernández y Rifá (2011), en el sentido de valorar el ejercicio de la reflexión crítica de lo vivido por alguien que somete sus autoanálisis al escrutinio de otras personas conocedoras del tema, lo contrasta con elementos teóricos pertinentes y con el contexto histórico social de lo vivido. Reconstruyo buena parte de mis experiencias vitales $y$, con base en ellas, señalo las distintas concepciones y prácticas que sobre el respeto a las diferencias $y$ el trato incluyente-excluyente poseen las personas con las que he interactuado. Al respecto destaco el carácter paradójico de los ámbitos y agentes familiares y educativos.

Nací hace 30 años en San José de Isnos (Huila), un pequeño municipio de tradición agropecuaria donde se destaca la producción panelera y cafetera. Es un municipio de alguna distinción turística por poseer un parque arqueológico con estatuaria agustiniana. Recuerdo que muy niño me familiaricé con frecuentes episodios de riñas violentas entre campesinos, en las cuales no eran extraños los muertos. Llegué al mundo en una familia católica de escasos recursos económicos, aparentemente sin ningún tipo de afectación. Cuando estaba cumpliendo un año de edad empecé a caminar, a dar los primeros pasos pero, de un momento a otro, tuve una fiebre con diarrea y me descompuse hasta quedar en un estado vegetativo. Mis padres me trajeron a Neiva y los médicos les dijeron que lo mejor era llevarme a la casa para morir allí con ellos y no acá en un hospital. Esa sentencia médica fue la primera actitud discriminatoria que sufrí, el primer intento de exclusión que, por fortuna, logré superar. De niño no sabía que mi vida entera sería una constante lucha contra el desconocimiento de mis derechos, contra las barreras tangibles e intangibles, conscientes e inconscientes, que las personas y la sociedad fabrican para impedir el desarrollo de sujetos como yo, con limitaciones físicas o con capacidades diferentes (SCD), como de modo acertado nos llama Belgich (2004), al poner el énfasis en lo que podemos hacer y no en lo que nos falta.

No desconozco que existe un debate académico, como lo proponen Gómez y Cuervo (2007) acerca de la definición de discapacidad, que va desde considerarla un asunto exclusivamente individual referido a carencias físicas, psicológicas y motrices, hasta asumirse con enfoques sociales como una condición limitante gestada en los contextos socioculturales (Ferreira, 2007). Sin evadir el debate, yo prefiero entenderla como integrada por los dos componentes anteriores que se retroalimentan. Estas concepciones descritas anteriormente siempre han estado presentes en mi vida, la primera, a partir de un diagnóstico médico apocalíptico, que colinda con la segunda, en cuanto a obstáculos y prejuicios para movilizarme y estudiar.

Pero si la violenta arrogancia de ciertos médicos que se creen con el poder divino de predecir la muerte, es censurable, loable es que otros se nieguen a perder sus pacientes mediante el estudio y la dedicación a cada caso que atienden. Estos últimos me salvaron cuando, gracias a un tío, fui internado en el Instituto Franklin Delano Roosvelt, de la ciudad de Bogotá. Pasé allí cuatro largos años, de los más duros de mi vida, sometido no sólo al aislamiento familiar sino a duros tratamientos. La distancia de San José de Isnos a Bogotá y la precariedad de recursos económicos no permitían que mis padres me acompañaran más que en visitas esporádicas.

1 - Para la elaboración de este ensayo conté con la asesoría del profesor Carlos Bolívar Bonilla Baquero 
La rutina en el Instituto era muy severa, casi militar, a los pacientes nos levantaban muy temprano, nos pedían que nos vistiéramos solos, yo tenía el problema de no poder ponerme las medias y sólo después de hacerlo podía pasar a comer. Ahora entiendo lo correcto de aquella exigencia, frente a una equivocada concepción de inclusión como asistencia paternalista, referida a que los demás hagan por uno acciones que uno mismo debe aprender a hacer. Después de comer seguía el trabajo de fisioterapia. Una tortura porque la fisioterapeuta era una señora gorda, pesada, que me hacía unos estiramientos muy dolorosos. Intentaba quitármela de encima con toda mi fuerza pero nunca pude.

Luego de la fisioterapia venia otro trabajo de estimulación con electricidad, muy incómodo, porque me ponían unos pequeños electrodos en los pies para estimular los nervios y, después de eso, trabajo con hidroterapia. En la tarde laboraba con el psicólogo, recuerdo que trabajaba mucho la coordinación fina en la elaboración de figuras, construir manualidades, castillos. Tuve varias cirugías dolorosas, me cortaron los tendones para estirar mis piernas y luego me enyesaron para conservar el estiramiento, así pasé meses. No podía dormir, soñaba con martillos y serruchos para liberar mis piernas del yeso. Muchas veces intenté escapar del Instituto.

Agradezco que entré al Franklin como un vegetal y salí consciente y con movilidad, restringida pero suficiente para decidirme a seguir adelante. Podía moverme por mí mismo pero con apoyo de barandas o la pared. Sin embargo, en medio de tanto tratamiento no hubo espacio para lo académico o escolar. Ignoro si esto es hoy todavía así o han incorporado el elemento curricular. Salí en cero, sin leer, ni escribir, menos saber de matemáticas o ciencias naturales. Al volver a Isnos ingresé a un preescolar de una amiga de mi madre, donde no hacía nada. Ahí la inclusión era dejarme hacer cualquier cosa. Pese a que intentaba escribir o pintar, la falta de control muscular manual no me lo permitía. Con los otros niños peleaba mucho. Admito que era agresivo, tal vez como reacción errónea por la frustración de ver a los demás en disposición de sus facultades plenas y yo estar limitado y, a la vez, por ser objeto de comentarios o pesares indebidos.

En la escuela no usaba la silla de ruedas. Nunca pensé en ella y me esforzaba para desplazarme por mis propios medios, inclusive competía con otros niños y con frecuencia los tumbaba y los golpeaba. No tenía el concepto teórico de la discapacidad, ese fue un concepto posterior. Fui indisciplinado, entraba a los salones y tomaba objetos de mis compañeros, como reglas y tijeras, para convertirlas en armas. También me escapaba de la escuela y deambulaba por mi pueblo (San José de Isnos) con facilidad. Era un pueblo pequeño y todos me conocían. El cambio drástico ocurre cuando entro al colegio en Pitalito. Para mí eso fue como si hubiera llegado a otro país: mucha gente desconocida, bastantes carros en las calles, andenes estrechos y congestionados. Ya no podía estar seguro ni solo en las calles, así que empecé a usar un caminador.

Ahora comprendo que las ciudades se hacen desde los intereses y expectativas de quienes no padecen ningún tipo de discapacidad. Son excluyentes de nosotros los SCD, con alguna limitación para movilizarnos en ellas. Se trata del autoritario concepto de las mayorías respaldado por el de "normalidad", impuesto al de las minorías "anormales". Por eso comparto con Blanco (2006) que tal dicotomía se debe y puede romper si: desde la inclusión se considera que la diversidad está dentro de lo "normal" y el énfasis está en desarrollar una educación que valore y respete las diferencias, viéndolas como una oportunidad para optimizar el desarrollo personal y social, y como un medio para enriquecer los procesos educativos. (p.10)

Mientras no sea así no avanzaremos, pese a la existencia de leyes que, por ejemplo, ordenan la reestructuración de las zonas públicas para generar accesos especiales a personas con limitaciones físicas; normas que son incumplidas. Las barreras arquitectónicas las viví en el Pitalito de los años noventa y las sigo viviendo en la Universidad Surcolombiana, en Neiva y en la Colombia de 2015. Admito los progresos normativos que, sobre el papel, reconocen el respeto a derechos fundamentales de minorías como a la que pertenezco. Pero cuestiono su inoperancia, generalmente por negligencia de las autoridades y administradores de las diversas instituciones. Lo mismo que por falta de organización y capacidad crítica de nosotros los afectados.

Llegué entonces al colegio en caminador. Un aparato incómodo, de cuatro patas, que tropezaba por todas partes. Pero al mismo tiempo empiezo a percibir un trato acogedor, los compañeros me colaboran, los profesores empiezan hacer adaptaciones a mis necesidades individuales para garantizar que se me respeten los ritmos y las particularidades en los procesos educativos, de acuerdo con la Declaración de las Américas. Sin teorías o normas muy claras siento que me incluyen en el devenir escolar, empiezo a entender la importancia suprema del trato afectuoso en los procesos incluyentes y hago mis primeros amigos. Lo mismo que mi primera amiga especial. En muchas ocasiones era literalmente alzado por los compañeros para ir a sitios donde no podía llegar con el caminador. Un día, obligado por la directora del colegio, fui a misa. En la iglesia vi una silla de ruedas, me senté en ella y aprecié su comodidad pero temía verme como un robot, como si en ella perdiera mi condición humana. No obstante, pedí una a mi familia.

Llegó la silla de ruedas y no me atrevía a desempacarla. La miraba y como que quería y no quería. Un día que no había nadie la destapé, la puse ahí y me senté. Me sentí muy incómodo, como un robot. Intenté moverla y resulta que cuando uno la mueve con un solo brazo ella no avanza sino que empieza a dar vueltas, y yo frustrado. La dejé un tiempo, después volví a 
intentarlo y ya fui al colegio con ella. Entonces dos compañeras me llevaban a la cafetería, al salón, a todos lados. Pensé que en adelante la silla sería parte de mi estilo y proyecto de vida. Le hice cambios estéticos y funcionales para adaptarla a mis gustos y necesidades personales, la pinté de negro y le puse un escudo reflectivo del fútbol norteamericano. Le suprimí los apoyabrazos para ganar comodidad en su manipulación.

Claro que la silla también trajo otros problemas como el del acompañamiento de una persona de la casa al colegio y viceversa. Empecé a sentir la dependencia del acompañante en la calle y, de pronto, un día escuché en la radio algo que cambió mi vida, habían instalado una casa, "La Camila", dedicada al cuidado y entrenamiento de perros de asistencia (ayuda técnica) y lazarillos (guías para invidentes), dirigida por un señor John Jairo Londoño. Tuve algo así como un insight, una revelación. Al mismo tiempo recordé que mi mamá odiaba los perros y que no me permitiría tener uno en casa. Pero aprovechando que un tío me ofreció una cachorra Pitbull, opté por llamar a "La Camila", en medio de muchas dudas, y logré una cita en mi casa con John Jairo.

Con él vimos la Pitbull que no resultó pura y sí muy chica para tirar la silla, fue descartada. Entonces el adiestrador me trajo cinco perros para estudiar el más indicado, la ideal era la de él, "Sacha", la mejor perra de rescate de la Cruz Roja Colombiana, que en principio me prestó y con ella empecé a disfrutar la efectividad y tranquilidad de sus servicios. Aprecié la no dependencia de otra persona $y$, sobre todo, la privacidad y autonomía (siempre relativa) de poder decidir yo mismo a dónde ir, en qué momento irme o quedarme en un sitio. Ya no discutiría más con una persona acompañante al respecto.

Con Sacha hubo un enamoramiento mutuo y una empatía total. Ella me asistía aun sin collar y para mí era motivo de orgullo su compañía. Me volví visitante casi permanente de "La Camila" y amigo especial de John Jairo. Acariciaba los perros, los bañaba y comencé de modo espontáneo a aprender asuntos sobre su cuidado y entrenamiento. Los beneficios que me brindaban estos animales me ayudaban a mejorar el control sobre mi vida y tenía mayor independencia y autoestima.

Hoy defiendo con vehemencia este tipo de intervención no convencional llamada terapia asistida con animales (TAA) que, según Oropesa, García, Puente, y Matute (2009) es: Una intervención directa y con objetivos prediseñados, donde participa un animal que reúne criterios específicos, como parte indispensable para el tratamiento. Ha sido ideada para propiciar beneficios físicos, sociales, emocionales y cognitivos en una gran variedad de entornos, de manera individual o en grupo, valiéndose para ello de diferentes animales. (p.2)
Esta terapia es una fuente de superación para los SCD con secuelas de enfermedades similares a las mías (hemiplejía por poliomielitis). Ya que según Ross (1983, citado en Gunter, 2002) en niños mental o emocionalmente afectados, la aceptación incondicional del animal y la responsabilidad de cuidarlo promueve en ellos un sentimiento de valía personal y autoestima. Por otro lado, a través de la TAA obtienen el reconocimiento de un otro que muchas veces no logran encontrar en las personas. Gunter (2002) resalta que estos sentimientos se amplifican cuando el paciente observa que los cuidados que puede otorgarle a otro ser vivo son exitosos y que además ese otro lo necesita y depende de él. En muchos programas de TAA se realizan actividades en las que el paciente adiestra al animal. Cuando la persona es capaz de hacer que este responda adecuadamente a sus órdenes y su terapeuta colabora apreciando los logros obtenidos, se va despertando en él un sentimiento de dominancia que sumado a la sensación de ser necesitado por el animal, contribuye a aumentar la confianza de los pacientes en sí mismos. Gutiérrez, Granados y Piar (2007) comparten estas ideas y agregan que la interacción favorece la independencia, el sentido de valor y utilidad, promoviendo un estado afectivo positivo, un aumento de la autoestima y sentido del logro.

Ahora estoy en capacidad de ofrecer este tipo de servicio profesional. Además no sólo funciona para estas limitaciones sino para resolver muchas otras dificultades de tipo psicológico, en particular de la infancia, como las relacionadas con problemas afectivos de aprendizajes escolares, inseguridad, timidez o tendencias violentas. Por ejemplo, en el estudio de Piqueras (2013) se compararon las bondades de la terapia cognitiva y la asistida con animales, para atender la depresión y se concluyó, entre otras, que ambas favorecen mejoras significativas en los estados de ánimo de los pacientes. Lo mismo que para contrarrestar sus sentimientos de inutilidad, indecisión, falta de confianza y baja estima. La psicología y la etología, lo mismo que el puente interdisciplinario que entre ellas se construye en la actualidad, demuestran que la sabiduría popular no siempre se equivoca: El perro es uno de los mejores amigos del hombre, después de conocer a muchas personas prefiero confiar en $\mathrm{mi}$ perro.

El contacto con John Jairo y "La Camila", sin darme cuenta, habían dotado a mi vida de una dimensión y un sentido trascendentales. Algo que se me hizo evidente cuando él puso en mis manos el libro "Principios Básicos del Aprendizaje", del psicólogo Rogert M. Tarpy. Leí ese libro y para mí fue claro que lo que se hacía con los perros estaba muy relacionado con la psicología. Ese texto me motivó de manera intensa a trabajar con los canes, todavía lo conservo, aunque en mal estado por mis tormentas emocionales. Además John Jairo decidió irse a Brasil y antes de hacerlo le dijo a mi mamá: doña Sonia, Julián necesita un perro, es ahora o nunca. Mi madre dijo que sí y conocí a "Nieves", una Golden Retriever. 
Como estaba tan acostumbrado a Sacha, en principio dudaba de Nieves, pero en un paseo con compañeros del colegio me puse a beber licor y, ya ebrio, decidí soltarla del collar. Al contrario de lo que pensé, la perra no se fue, no me abandonó, permaneció todo el tiempo conmigo. Nieves progresó en su labor de tirar la silla y en aprender a comportarse en los lugares donde yo tenía que estar. Fue mi verdadera primera acompañante. Con ella me liberé definitivamente de depender de otras personas para movilizarme o de pagar taxis.

Ahora que reflexiono para escribir este ensayo, encuentro que a John Jairo tengo mucho que agradecerle. No sólo por mostrarme el camino con los perros sino por enseñarme a ver el mundo de otra manera. Él sí era incluyente, pues me trataba como su semejante y me invitaba a todo tipo de actividades sin considerarme incapaz. Aprendí que esa es otra principal cualidad de las personas incluyentes, ver al otro capaz de superación y, en consecuencia, promover sus capacidades.

Por lo general la gente se equivoca al verlo a uno como un caso perdido y asume una de dos posturas igualmente negativas: el pesar sobreprotector o la indiferencia insolidaria. Con la primera, se tiende a hacerle a uno todo sin notar que así lo limitan más al impedir un desarrollo autónomo. Muchas veces uno mismo cae en la trampa de aceptar estas ayudas y se conforma con esperarlas cultivando la dependencia. La segunda actitud me hace sentir ignorado y en definitiva excluido. Esta última corresponde, según Palacios (2008), al modelo de prescindencia: "Como se ha adelantado, un rasgo esencial del modelo de prescindencia es la consideración de que las personas con discapacidad no tienen nada que aportar a la comunidad. La diversidad funcional es vista como una situación desgraciada" (p.38).

De modo tal que antes de conocer a John Jairo, mi vida transcurría entre la casa y el colegio. En mi hogar la televisión se convirtió en mi más importante compañía recreativa y educativa, todavía hoy es para mí una opción infaltable. Sé que en ella hay mucho programa bobo y enajenante pero yo me refiero a la televisión cultural (Discovery Chanel, Animal Planet, National Geographic), a través de la cual conocí de ciencias y el mundo lejano. El mundo inmediato, externo a mi casa y mi colegio, me lo mostró John Jairo.

Él me llevaba a atender perros enfermos y de paso me enseñaba a inyectarlos, a cuidarlos. Como él era socorrista de la Defensa Civil me involucró en ese campo, que me fascina. Con los socorristas participé de entrenamientos duros y tuve experiencias increíbles como la de hacer rápel a una altura de $20030 \mathrm{~m}$. Me volví muy bueno para eso, lo mismo que en las pruebas de conocimientos y llegué a ser entrenador. Experiencias que ni mi propio padre me permitía y por las cuales me castigó algunas veces.

Luego incursioné en Bomberos, todavía pertenezco a este organismo y espero ver a sus integrantes en mi graduación de psicólogo. Por el trato paritario logré allí bastante desarrollo personal y social, por eso, para mi graduación de bachiller, invité a su comandante. Además ese día recibí la distinción Andrés Bello por el segundo puesto en el Huila en las pruebas de Estado. Ya John Jairo había muerto y sentía que el comandante de los bomberos era su representación. La verdad yo no quería ir a esa ceremonia pero una amiga muy especial y la presencia del comandante, me motivaron. Me sorprendieron ese día con la llegada del carro de bomberos con toda la brigada engalanada. Me subieron al vehículo y me pasearon con ellos.

Pese a todas las atenciones me costaba superar la falta del apoyo de John Jairo y como mis amigos del colegio empezaron a irse a estudiar a otras ciudades, me sentía solo. Una noche intenté quitarme la vida. Luego tuve otras crisis similares pero, para bien y con la ayuda de amigos y familiares, las asimilé. Ahora, con el estudio de la psicología me comprendo y comprendo mejor a los demás. Me siento capaz de poner mis conocimientos al servicio de otras personas, en especial si ellas tienen limitaciones similares a las mías. Aunque estudiar no ha sido fácil porque, en unas ocasiones, encuentro inclusión, acogida y afecto. En otras oportunidades me estrello con todo lo contrario, tratos discriminatorios, rechazos y negación de la singularidad bajo la figura aparente de la homogeneidad y el igualitarismo.

En el colegio ya viví esta paradoja. Por un lado, hallé buenas disposiciones emocionales a acogerme, en parte porque no era el único en esas condiciones y porque el plantel tenía una orientación religiosa. Por otro lado, el tratamiento pedagógico no era el mejor, pues nadie estaba preparado para atenderme de manera adecuada. Carencia estudiada en Colombia por Padilla (2011) quien encontró en una muestra de 336 maestros de distintos colegios bogotanos que sólo el $28.9 \%$ se siente preparado para atender discapacidades físicas y únicamente el $19.9 \%$ y el $19.3 \%$, respectivamente, para responder por discapacidades sensoriales y cognitivas. No obstante a los incrédulos logré aprender a leer pero, por mis dificultades manuales motrices, no pude escribir. Hablar y leer me permitieron rendir en ciencias naturales, sociales y humanas, ayudado con los recursos didácticos básicos de la prueba oral y del trabajo grupal. Mi estudio consistía en poner cierta atención en las clases y ver, como ya dije, mucha televisión cultural. En matemáticas, por los exámenes escritos, no pude encontrar un camino, ni pudieron los maestros ayudarme a encontrarlo. Igual me ocurrió con educación física.

Esto muestra que los maestros ignoran o no estudian la condición de los SCD, como yo, y así no pueden ayudarnos. Por ejemplo, no saben que una limitación motriz no supone automáticamente una incapacidad intelectual. $O$ que la afectividad puesta en el vínculo docente estudiante es decisiva para superar dificultades motrices y cognitivas, tal como afirma Arnaiz (1999).

La influencia de los factores emocionales en el apren- 
dizaje tiene cada vez más credibilidad por cuanto que los sentimientos y las capacidades afectivas están íntimamente implicados en el proceso de aprender. La propia personalidad, la autoestima, las expectativas que el estudiante tiene sobre el profesor, así como el concepto y las expectativas que el profesor tiene sobre el propio alumno juegan un papel fundamental $y$ determinante en el proceso de enseñanza-aprendizaje (16).

Pienso entonces que sin claridad teórica o sin proponérselo, en el colegio optaron por hacerse los de la vista gorda con mis deficiencias a cambio de favorecer y creer en mis potencialidades. Esta es una inteligente manera de hacer inclusión educativa básica, pues si una institución le exige a un SCD que rinda igual que los demás en todas las áreas, esa persona no terminará jamás sus estudios. Así la excluirán. Sobre la escritura intenté, sin éxito, muchas alternativas, inclusive la de las máquinas eléctricas. Ahora es un poco más fácil suplir esta limitación con ayuda de programas informáticos como Dragon Naturally Speaking y TextAloud, que permiten grabar y transcribir la voz. Otra opción incluyente es la aplicada para escribir este ensayo. Consiste en grabar lo que uno desea comunicar y pedir a otra persona con mayor experiencia en escritura que le colabore en pulir la redacción. Uno determina entonces si acepta o no lo que esa persona le propone.

Al terminar el bachillerato recuerdo dos episodios fuertes de exclusión. Uno fue el de la presentación de las pruebas de Estado, pues se suponía que me asistiría en ellas un delegado oficial con experiencia en estos casos. Pasaban y pasaban las horas y nada que el delegado llegaba. Entonces un profesor decidió que otra persona me asistiera. Tuve que correr contra el tiempo para contestar tantas preguntas. El otro fue protagonizado por mi madre, quien tal vez por sus temores y en actitud supuestamente proteccionista, manifestó negarme la posibilidad de ir a la universidad. Apoyada por la esposa de un tío, médica patóloga, me recalcaba que una persona como yo, que ni siquiera podía comer solo, no tenía opción en la $U$. Que mejor me quedara en casa y montara un centro de adiestramiento canino. Pero yo insistí en que sí podía y en que quería estudiar psicología. Y aquí estoy próximo a graduarme (espero que cuando este ensayo sea publicado, ya tenga mi título).

Debo aclarar que esta actitud materna no corresponde a un acto de mala fe. Por el contrario, según un estudio australiano sobre el papel de las madres con hijos SCD, coordinado por Brock (2015), se encontró que superproteger al hijo es uno de cinco estilos de crianza, motivados por imaginarios sociales relacionados con el deber de cumplir la expectativa de ser buena madre. No dudo que mi mamá entendía que al intentar tenerme cerca cumplía su deber de buena madre. Lo que no comprendía era que su expectativa de maternidad correcta afectaba mi autonomía y proyecto de vida.

Antes de llegar a la Usco me matriculé en una universidad privada, en un Programa a distancia, básica- mente por Internet. Por aquellos tiempos murió Nieves y conocí a "Conrad". Encontré esa perra en los puros huesos, con un ojo reventado. Me costó $\$ 300.000$, la curé, la cuidé y se puso hermosa. En el primer parto dio nueve cachorros, los vendí y gané casi $\$ 2^{\top} 000.000$, compré un computador para mis estudios universitarios. Estudiar a distancia mediante Internet tampoco fue fácil. Los tiempos disponibles para contestar pruebas no contemplaban personas con mis limitaciones motrices y no alcanzaba a responder, como sí lo hacían mis compañeros.

Igual ocurría con aspectos como la extensión de los trabajos escritos. Mientras que otros estudiantes no tenían problemas para escribir 20 o 30 páginas, para mí lograr 5 o 10 era una labor titánica. Además, en esa época Internet no era tan eficiente como hoy, en pleno foro, por ejemplo, la red se caía. Las tutorías también se afectaban por estas fallas. Todas estas situaciones iban en contra de los acuerdos expresados en la Declaración de Salamanca (1994) donde se afirma que:

Los programas de estudios deben adaptarse a las necesidades de los estudiantes y no al revés. Por consiguiente, las escuelas deberán ofrecer opciones curriculares que se adapten a los estudiantes con capacidades e intereses diferentes. Los estudiantes con necesidades educativas especiales deben recibir un apoyo adicional en el programa regular de estudios, en vez de seguir un programa de estudios diferente. El principio rector será el de dar a todos los estudiantes la misma educación, con la ayuda adicional necesaria para aquéllos que la requieran (22.).

Por estos motivos empecé a considerar mi retiro y en quinto semestre desistí. Una ganancia impensada de esa experiencia universitaria fue mi primera experiencia amorosa. Ocurrió con la compañera que más nos contactábamos en Internet. Ella era mayor que yo, supuestamente divorciada y con dos hijos. Por ella, contra el deseo de mi familia, me fui hasta Medellín, me alojé en un hotel y compartimos la intimidad. Pero resultó casada, no divorciada, y tuve que esconderme y escaparme para evitar problemas con su esposo. El señor ofendido me amenazó y todo esto me afectó bastante. Acudí por primera vez a un psicólogo que me ayudó a resolver la crisis.

Este encuentro con la faceta clínica de la psicología fue favorable para persistir en la idea de seguir estudiando. Después tuve otra experiencia amorosa conflictiva con una señora separada. Alcancé a convivir con ella un tiempo pero no funcionó y regresé a mi casa. Mi padre fue muy fuerte conmigo al tratar estas experiencias amorosas. Nos enfrentábamos en ocasiones con dureza de parte y parte. Ahora entiendo que, como mi madre, su amor y temor por mí lo llevaban a superprotegerme y, por eso, a negarme la posibilidad y capacidad de mi independencia, erotismo y autonomía.

Dejé a Pitalito y llegué a Neiva por otra de mis crisis, por otro intento de suicidio que me postró en cama. Me trajeron a esta ciudad en búsqueda de mejores cuida- 
dos médicos. De la atención médica me remitieron a la psiquiátrica y de allí a la unidad mental del hospital. Apenas crucé la puerta de esa unidad se me tiraron encima unos enfermeros, me amarraron de pies y manos a una cama y me suministraron calmantes. Me aislaron. Los otros pacientes trataban de acercárseme a preguntar por mi nombre y los enfermeros los retiraban diciéndoles que yo era muy agresivo. Estuve amarrado como dos días, inclusive cuando llamé a una enfermera para decirle que necesitaba ir al baño, me respondió que hiciera mis necesidades en la cama. Así me tocó hacerlo. Me sentí peor que en una cárcel.

El día que me soltaron de la cama, como a las cinco de la mañana, me metieron de inmediato bajo una ducha fría. Como estaba mal alimentado, estresado e inmovilizado, esa ducha casi me mata de hipotermia. Me recuperé poco a poco. Me trajeron la silla de ruedas y empecé a deambular por la unidad mental, a conocer a todo el personal. Sin embargo, una vez tuve una experiencia mental extraordinaria, sentí que había llegado al reino de los espíritus hambrientos, del que habla el Budismo, uno de los reinos más bajos. Allí vi a las personas que se relacionaban con mi situación, como en una obra de teatro, todos en pena. Estaba John Jairo que, en mi visión, había matado a su madre. Vi al esposo de una de mis exnovias. Más tarde comprendí que en la complejidad del cerebro y la mente humana estas mezclas de realidad y ficción, de conciencia e inconsciencia, son frecuentes y no necesariamente propias de enfermos ni de la locura.

Entablé amistad con algunos enfermeros auxiliares y pacientes, en especial con dos militares acuerpados, que se convirtieron en mis guardaespaldas. El tiempo pasaba y no me dejaban salir. Me empezó a asaltar la duda sobre mi propia capacidad mental, a creer que ya no me recuperaría y que permanecería ahí por siempre. Miraba mucho una puerta que yo suponía conducía la calle, pero era la puerta de entrada a la Facultad de Salud de la Universidad Surcolombiana, donde estaban las carreras de Medicina, Psicología y Enfermería. ¿Cómo podía imaginar entonces que una crisis de mi vida me pondría frente a una salida, concreta y literal, a mi futuro profesional?

El azar favorable a mi recuperación y reencuentro con un proyecto de vida tuvo otro impulso definitivo, cuando una practicante de enfermería se llevó voluntariamente mis ropas sucias para su casa, las lavó y me las regresó. Ese gesto me conmovió. Las enfermeras con sus buenos tratos, cálidos, personales y amorosos, encarnan la ética del cuidado, orientada a la protección y el no daño del semejante, defendida por investigadoras como Gilligan (1985) y Noddings (2002). Según esta última: En la teoría que defiendo, la atención en tanto que orientación moral requiere receptividad, desplazamiento de las motivaciones (que la energía de la persona que atiende se canalice hacia los proyectos o las necesidades de la persona atendida) y realización completa en la persona atendida. (p. 25)

De esta manera las enfermeras resultan mucho más terapéuticas que los médicos con sus frías relaciones sociales e, inclusive, que sus medicinas. Afirmo esto porque la adherencia a los tratamientos depende en buena medida de la confianza y empatía generada entre médicos y pacientes. Como estas cualidades psicológicas fallan tanto en muchos de ellos, las enfermeras suelen compensar la balanza.

Abandoné al fin la unidad mental del hospital y volví a conversar con el psicólogo de Pitalito, que me animó a trabajar como instructor en el Servicio Nacional de Aprendizaje. Le manifesté que eso no era lo mío y me recordó una aspiración anterior, me dijo, muy seguro, estudie psicología. Me inscribí y pasé en esa carrera, en la Universidad Surcolombiana. Empiezan una vez más las dudas de mi familia sobre mis capacidades, mis padres consideraban imposible que pudiera vivir solo. Me propusieron pagarme una habitación en Pitalito para que me "independizara", pero cerca de ellos, para que no me viniera a Neiva. Todo lo veían problemático: la comida, el desplazamiento, las exigencias académicas en prácticas o salidas al campo.

En mi reflexión actual entiendo que la primera barrera excluyente nace en la propia familia, por el amor indebido que enmascara los miedos paternales $y$ maternales. Y esto aplica no sólo para sujetos como yo, con limitaciones motrices. Recuerdo que al respecto leí un escrito de un profesor mío en el que argumentaba que a los hijos no hay que amarlos mucho sino amarlos bien. Explicaba que demasiado amor tiende a asfixiar al hijo, a desconocer sus iniciativas, proyectos y capacidades. A imponer inconscientemente los deseos de los padres a los hijos, al superproteger al otro se le inhibe.

De haber atendido los temores-amores de mis padres no hubiera estudiado psicología, estaría viviendo en su casa, en dependencia de ellos. Por lo dicho sé que en casos como el mío (y en muchos de sujetos normales) la principal labor psicológica no debe recaer en el joven sino en los padres. En estos casos el psicólogo no debe intentar adaptar al niño o joven a las demandas de sus progenitores, sino trabajar con estos para que acepten las capacidades que no pueden o no quieren ver en sus hijos, se las respeten y las apoyen. Tal como DeMause (1994) plantea, concebir a los hijos como seres diferentes a uno (padre), capaces de autonomía, es muy saludable para su desarrollo. En cambio, convertirlos en proyección de deseos insatisfechos o temores inconscientes, es perjudicial.

Pactamos al fin que vendría a Neiva a estudiar pero con vivienda donde una tía. Me mantenían así mis papás el control y el cerco afectivo de sus temores. Mi tía resultó ser una mamá más posesiva que la mía, me controlaba el color y tipo de ropa, del calzado, de todo. Me exigía que pusiera una toalla antes de sentarme en sus sillas para no sudarlas. Al comienzo pensé que me tocaba aceptar todas estas exigencias pero luego entendí que allí no podía seguir viviendo. Además, mi tía vivía en un barrio alejado de la Facultad de Salud, donde yo estudiaba, y eso me obligaba a pagar taxis y a vivir las 
incomodidades de subir y bajar del vehículo. Decidí irme a una habitación humilde pero muy cerca de la Facultad, contra el sentir y el pensar de mis padres.

Por temor y desconocimiento de las normas al respecto llegué a la universidad sin mi perra. Traje únicamente un video del trabajo que hacía con los animales. Mi primera impresión de la universidad fue favorable, me pareció muy bonita y algo intimidante por su tamaño, pues me perdía con facilidad. Comencé a recibir clases, a conocer a mis profesores y compañeros. Emprendí una nueva etapa de inclusión exclusión en la vida universitaria. Una primera experiencia incluyente fue la de plantearle al Decano de aquel entonces la necesidad de mi perra para tirar la silla. La respuesta inmediata y positiva me llenó de alegría.

Al mismo tiempo tropecé con las barreras arquitectónicas, para pasar de un edificio a otro no había rampas. Llegar a los baños, la biblioteca o la cafetería restaurante, era imposible. Inicié mis reclamos y con una lentitud desesperante empezaron a aparecer las primeras rampitas, estrechas y poco técnicas pero mejor que no tenerlas. Las enfermeras reaparecen en mi vida con su actitud humanitaria incluyente. Un día, una profesora de esa carrera ve mis dificultades para comer y me pregunta cómo puede colaborarme. Le indico y ella lo hace. Luego me presenta a sus estudiantes y les dice que cuando puedan ayudarme con mis asuntos, lo hagan. En efecto, son las estudiantes de enfermería las que más me auxilian en muchas oportunidades.

En la universidad en general y en particular con mis compañeros de psicología viví y vivo momentos y experiencias de "amorodio", de inclusión exclusión. Para empezar debo criticar que pese a la universidad indagar, a través de su página web, si uno como estudiante recién matriculado tiene alguna discapacidad, esta información no sirve para nada. A mí nadie me contestó ni me informó de la semana de inducción y por eso no llegué a ella. Cuando me acerqué a mi grupo era un extraño ante un colectivo que ya forjaba sus primeros vínculos, entre quienes sí asistieron a la inducción. Tampoco supe de modo oportuno sobre Bienestar Universitario y sus ofertas. Menos pude contar con un psicólogo que atendiera mis dudas y temores iniciales. Peor aún, todavía hoy la universidad no atiende la situación de 13 estudiantes SCD registrados como tales.

Nadie en el Programa de Psicología me llamó para preguntarme qué necesitaba o cómo podría atenderme pedagógicamente en sus clases. Lo mismo ocurrió cuando, producto de unas deliberaciones epistemológicas y administrativas, decidieron trasladar el Programa de la Facultad de Salud a la de Ciencias Sociales, nadie consideró mi particularidad y condición de vivienda y desplazamiento. Admito que casi todos los docentes trataban, sobre la marcha, de adaptar trabajos o ejercicios a mi singularidad, pero esto no corresponde una política institucional clara y metódica de capacitación profesoral. Son iniciativas personales y esporádicas, no sistemáticas, como debe ser. Por ejemplo, mi profesor consejero me ofreció algunas normas institucionales que me podrían servir, pero más allá de eso, Bienestar Universitario piensa principalmente en estudiantes "normales", no en los que poseemos alguna discapacidad.

En esta casuística de las iniciativas personales, otras dos profesoras, por separado, se me acercaron alguna vez a preguntar por mi desempeño en la carrera y a ofrecerme libros. Inclusive una de ellas me invitó a un importante congreso académico en Medellín y me presentó a algunos de los principales conferencistas. Son experiencias que agradezco y no olvido. Quiero narrar que algunos profesores jamás hicieron alguna diferenciación o discriminación positiva la cual es definida según Eguzki (2009), como: "Discriminar positivamente es tratar de manera diferente aquellos que son diferentes dando más a los que tienen menos. Se toma en consideración una desigualdad de situación o se intenta reducir esta desigualdad" (p.2). Peor aún, un catedrático llegó a afirmar que las personas que poseen una discapacidad no deberían venir al mundo, argumentando que es una filosofía de países europeos. Lo denuncié ante Control Interno de la Universidad, oficina que no hizo nada y archivó el caso. Es evidente que este tipo de docentes nunca han leído a autoras como Nussbaum (2014), defensoras de la dignidad humana y la justicia para todas las personas, inclusive para aquellas como yo. Y para una justicia plena, dice esta pensadora, es indispensable lo que no tiene este profesor, sensibilidad, amor por el prójimo.

En otra experiencia relacionada con el desconocimiento de nuestras particularidades como SCD, una profesora se alarmó porque en su clase me quedé dormido y atribuyó mi sueño a mi supuesta discapacidad, vio mi dormir como patología. Cabe resaltar que los docentes de la Universidad cada semestre tienen eventos de capacitación, pero jamás contemplan en ellos la atención a los SCD. Pese a que en el artículo 13 de la Ley 361 de 1997 se establece que el Ministerio de Educación Nacional definirá el mecanismo para realizar el diseño, producción y difusión de materiales educativos especializados, así como de estrategias de capacitación y actualización para docentes en servicio.

Sufrí también con las evaluaciones. La Universidad exige que los docentes presenten al iniciar cada curso una propuesta de programación y de evaluación. Nunca un docente me invitó a considerar mi punto de vista al respecto. Debo confesar que me faltó valor para reclamar allí mismo. Otro ejemplo de la falta de capacitación de los profesores, el cual se convirtió en una persecución debido a la falta de valoración de mis capacidades, lo viví en el curso de psicología de la salud. Al combinar teoría y práctica nos enseñan que debemos aplicar los conocimientos al entrar en contacto con otras personas pero, sin capacidad legal de intervenir como tratantes, lo cual genera una cierta contradicción, ya que el profesor titular no siempre puede estar presente en las prácticas. 
Dada mi experiencia vital y conocimiento sobre los perros de terapia a personas con limitaciones físicas y cognitivas, ofrecí aplicar este conocimiento y logré apoyo de ciertas personas en el hospital, menos de la titular del curso. Otros profesores del Programa, sin vínculo directo con el caso, también se opusieron alegando mi incapacidad para ello. Me sentí como con mis padres cuando me vaticinaban fracaso en la vida académica y en vivir solo en Neiva. Creo que es un caso desafortunado de academicismo, como no tenía un título en ese campo, invalidaron mi experiencia de vida. Vieron mi fortaleza como amenaza. A ningún docente se le ocurrió aprovechar pedagógica y psicológicamente mi experiencia para investigar, educar o hacer proyección social. Todo lo contrario a como actuó John Jairo.

Con base en lo expuesto me permito concluir que familiares, educadores, psicólogos y otros expertos deberían comprender que, además de sus propios esfuerzos por favorecer la inclusión social, instituciones y grupos no académicos como los bomberos, la Cruz Roja, la Defensa Civil y los equipos de deportes, pueden ofrecer experiencias reales de inclusión a los SCD, experiencias que lo hacen sentir a uno un igual frente a los demás. Destaco aquí la importancia que poseen las actividades físicas y deportivas, a través de las cuales podemos fortalecer el cuerpo y el espíritu, una saludable corporeidad, mientras cultivamos la disciplina, el control emocional frente a la derrota y la victoria (tolerancia a la frustración) y se ensanchan las relaciones sociales. Lo ideal sería que para estos casos los integrantes de las instituciones formales e informales señaladas, asumieran una actitud de mutua colaboración.

El papel de los animales como mascotas o como perros de servicio y compañía es fundamental para la adquisición de nuestra autonomía y responsabilidad, mediante su cuidado. Lo mismo que para liberar a la familia de una permanente atención sobre nuestra cotidianidad. Mucho mejor si familiares, educadores y psicólogos estudian o promueven el empleo sistemático de terapias asistidas con anímales. El perro lazarillo es más conveniente para un SCD joven que una silla motorizada, pues esta última priva al usuario de aprender a ejercitarse por sí mismo para resolver asuntos de su movilidad, con el agravante de propiciar el dañino sedentarismo.

Las instituciones educativas están en deuda con nosotros. Deben cumplir las normas especiales que el Estado ha diseñado para impulsar la inclusión y garantizar nuestros derechos. Deberían crear un nivel introductorio, propedéutico o cero, en todas ellas, para ubicar, orientar y contextualizar al SCD. El concepto de discriminación positiva es clave si en verdad nos quieren incluir, ya que el demagógico igualitarismo nos pone en desventaja y riesgo de exclusión del sistema escolar. También deben adquirir infraes-tructura de movilidad, materiales didácticos y tecnológicos apropiados a nuestras necesidades. Pero, sobre todo, capacitar a sus docentes y monitores en atender las demandas especiales del SCD, mediante actitudes amigables, adaptaciones curriculares pertinentes, metodologías de enseñanza y técnicas de evaluación aplicadas a los casos particulares.

El estudio comparativo, entre seis países de la Unión Europea, de López-Torrijo (2009) acerca de la atención a escolares con necesidades especiales, ratifica esta conclusión al destacar que La formación inicial y continua de los profesionales que atienden a alumnos con discapacidades graves y permanentes debe incluir su capacitación para la atención educativa a la diversidad de todo el alumnado, porque sobre ellos descansa la responsabilidad mayor de la educación inclusiva. Esta formación debe completarse con la especialización en postgrados o master que asegure la habilitación profesional de los profesionales de apoyo y especialistas. (p. 15)

Padres y madres de familia tienen que entender que la mejor paternidad y maternidad en estos casos no es la de sobreproteger al SCD. No deberían confundir el amor con el temor para impedirnos salir de la casa y construir nuestros proyectos de vida. La asesoría psicológica dirigida a que padres y madres dejen de vernos como incapaces es decisiva. Para que aprendan a confiar en nuestras potencialidades y para que permitan el apoyo de otras personas que nos ofrecen alternativas de superación.

Nosotros, los SCD, tenemos que organizarnos corporativamente para luchar por nuestros derechos. En países como el nuestro, gobernantes y funcionarios públicos están mal acostumbrados a que, si no escuchan y ven la presión de la protesta de los ciudadanos, no atienden sus responsabilidades. Finalmente se trata de, como lo propone el Índice de Inclusión (Booth, Ainscow, Black-Hawkins, Vaughan y Shaw, 2000), de trabajar para construir culturas, políticas y prácticas inclusivas en la escuela y la sociedad.

\section{Referencias}

Arnaiz, P. (1999). El reto de educar en una sociedad multicultural $y$ desigual. España: Universidad de Murcia. Recuperado de http://members.fortunecity.com/camino2001/Inclusion2.htm

Belgich, H. (2004). Sujetos con capacidades diferentes: Sexualidad y subjetivación. Armenia: Kinesis.

Blanco, R. (2006). La equidad y la inclusión social: Uno de los desafíos de la educación y la escuela hoy. Revista Electrónica lberoamericana sobre Calidad, Eficacia y Cambio en Educación. 4 (3).

Booth, T., Ainscow, M., Black-Hawkins, K., Vaughan, M., y Shaw, L. (2000). Indice de inclusión: Desarrollando el aprendizaje y la participación en las escuelas. Recuperado de:

http://www.mineduc.cl/usuarios/edu.especial/doc/2013051512 56510.Indice_de_inclusion.pdf

Brock, S. (2015, enero). Experiencias de madres con hijos con discapacidad. Afin, 68. Recuperado de: http://ddd.uab.cat/pub /afin/afinSPA/afin_a2015m1n68iSPA.pdf.

DeMause, LL. (1994). Historia de la infancia. Madrid: Alianza.

Eguzki, U. (2009, octubre/diciembre). Las políticas de discriminación positiva. Revista de Estudios Políticos, 146, 181-213. Recuperado de: http://www.cepc.gob.es/publicaciones/revistas/revistas electronicas?IDR $=3 \& I D N=680 \& I D A=27541$.

Ferreira, M. (2007). Prácticas sociales, identidad y estratificación: Tres vértices de un hecho social, la discapacidad. Intersticios. Revista Sociológica de Pensamiento Crítico, 1, (2). Recuperado de http://www.intersticios.es 
Gilligan, C. (1985). La moral y la teoría: Psicología del desarrollo femenino. México: Fondo de Cultura Económica.

Gómez, C, A., y Cuervo, C. (2007). Conceptualización de discapacidad: Reflexiones para Colombia. Bogotá: Universidad Nacional de Colombia.

Gunter, B. (2002). Animales domésticos: Psicología de sus dueños. Barcelona: Paidós.

Gutiérrez, G., Granados, D., y Piar, N. (2007). Interacciones humanoanimal: Características e implicaciones para el bienestar de los humanos. Revista Colombiana de Psicología, 16, 163-184.

Hernández, F., y Rifa, M. (2011). Investigación autobiográfica y cambio social. Barcelona: Octaedro

López-Torrijo, M. (2009). La inclusión educativa de los alumnos con discapacidades graves y permanentes en la Unión Europea. Revista Electrónica de Imvestigación y Evaluación Educativa, 15 (1), 1-20. Recuperado de:

http://www.uv.es/RELIEVE/v15n1/RELIEVEv15n1_5.htm

Noddings, N. (2002). Atención, justicia y equidad. En N. Noddings et al. Justicia y cuidado (pp. 15-30). Barcelona: Idea Books.

Nussbaum, M. (2014). Emociones políticas. ¿Por qué el amor es importante para la justicia? Barcelona: Paidós.

Oropesa, P., García, I., Puente, V., y Matute, Y. (2009). Terapia asistida con animales como fuente de recurso en el tratamiento rehabilitador. Medisan, $13(6)$

Padilla, A. (2011). Inclusión educativa de personas con discapacidad. Revista Colombiana de Psiquiatría, 40 (4).670-699. Recuperado de http:/ www.scielo.org.co/pdf/rcp/v40n4/v40n4a07

Palacios, A. (2008). El modelo social de discapacidad: Orígenes, caracterización y plasmación en la Convención Internacional sobre los derechos de las personas con discapacidad. Madrid: Cinca.

Piqueras, C. (2013). Terapia cognitiva y terapia asistida con animales en el tratamiento de la depresión (Tesina, Universidad de Belgrano, Argentina). Recuperado de: http://www.ub.edu.ar/investigaciones.

Unesco (2004). Declaración de Salamanca. Recuperado de www.unesco.org/education/pdf/SALAMA_S.PDF 